\title{
A Study on Advertising Strategy based on the Impact of a Business Reputation on the Market
}

\author{
Mayur Qumer Collins ${ }^{1}$ and Estrella Galbraith ${ }^{2}$ \\ ${ }^{1,2}$ Western Sydney University, Rydalmere, Australia \\ ${ }^{1}$ mayur.collins@westernsydney.edu.au, ${ }^{2}$ e.galbraith@westernsydney.edu.au
}

\begin{abstract}
With the development of internet technology, the consumer market has also changed, and the company's sales model has also been updated with the individual needs of customers. The dual-channel dynamic control model based on the influence of business reputation studied in this paper is more complete and closer to reality than the traditional hybrid dual-channel model. This article discusses the problem of advertising investment in the dual-channel supply chain consisting of traditional retail channels and online electronic direct sales channels, and the influence of brand business reputation on market competition. It is concluded that both market competition and business reputation exist at the same time. Under the optimal advertising investment, further analysis of the changes in advertising investment is under the influence of different factors. The research results show that in a dual-channel supply chain, in addition to advertising, business reputation also has an impact on market competition. When the business reputation has a greater impact on the market share, the advertising investment on the brand should be increased, thereby increasing the brand's business reputation in a specific market and promoting the retailer's ability to occupy the market, and vice versa. The research results of this paper can provide a reference for the dynamic advertising investment decision of the dual-channel supply chain under the influence of business reputation.
\end{abstract}

Keywords: Business reputation, Market competition, Advertising, Market share

\section{Introduction}

With the popularization and application of e-commerce and the development of internet technology, the consumer market has undergone revolutionary changes. More and more companies have adopted a modern sales model in which both traditional retail and online direct sales channels coexist [1]. The new sales model provides value-for-money products and a convenient and fast consumer experience through the Internet and provides an opportunity for traditional brand companies to contact an increasingly large online consumer group.

Retailers in the supply chain advertise the products they sell to occupy market share and maximize their profits. Advertising investment is an important means for retailers to occupy the market. Multiple retailers are often involved in a mixed dual-channel supply chain, which will inevitably have a mutually competitive effect. The advertising investment of retailers in the traditional retail market and the electronic direct sales market has always been a hot spot for business circles and scholars. In the early days, Lanchester [2] analyzed the decision-making of two competitors in terms of advertising investment under the dynamic changes in market

Article history:

Received (May 6, 2021), Review Result (June 15, 2021), Accepted (August 30, 2021) 
share. Vidale et al. [3] proposed the relationship between the rate of change of advertising investment and sales of advertising investment on this basis. Nerlove et al. [4] used business reputation as a new tool to improve the original advertising investment model, proposed that advertising is a direct channel to increase business reputation, and analyzed and demonstrated that business reputation is a product market demand. The impact of this indirectly affects the decision-making on the amount of advertising investment. Erickson [5] and Chintagunta et al. [6] considered that advertising strategy is a dynamic change and oligopoly in reality, and proposed a dynamic Nash equilibrium game model of advertising strategy, which solved the optimal time and optimal advertising investment. Profit decision-making problem. Over time, more and more people analyze and study the game of this kind of advertising strategy problem. Davis [7] divides the market according to the region and the type of consumers for real retailers, and uses this to make corresponding advertising strategies, and draws the importance of multidimensional market research. Buratto et al. [8] proposed multiple factors to consider the problem of complex markets. Different markets may have different consumer groups, different consumer groups have different social backgrounds, different consumer preferences, and different consumption levels, all of which affect the total amount of sales. Jorgensen et al. [9] assumed that sales profits are affected by business reputation and advertising investment and that sales profits diminish with the marginal profit of business reputation. Research suggests that the retailer's advertising investment has a positive impact on the retailer's commercial reputation.

Judging from the existing research, many studies consider the impact of product prices and service levels of different channels on the profits of retailers in the discussion of the hybrid dual-channel supply chain competition model. There are little researches on mixed-channel competitive advertising strategies. In reality, consumers will consider the comprehensive factors of the product when making channel selection decisions. As an invisible attribute of an enterprise, business reputation on the one hand stimulates the enterprise to continuously improve itself and form a good market competition order. On the other hand, it is impacting the product market and tapping the market potential. Business reputation has become more and more important in product competition. Looking back on previous related studies, business reputation is mostly taken as a consideration to improve the advertising model, and there is a lack of targeted research on the dynamic changes of business reputation under the conditions of channel competition and the impact on optimal advertising investment. Different from existing research, this article considers the impact of changes in business reputation on market share, comprehensive business reputation, market competition, and advertising investment on target profits. Using the thinking of complex market issues, this article combines business reputation and market competition at the same time. Consider, build a competitive environment for two retailers and two markets, and establish a dual-channel supply chain competitive advertising strategy model. Analyze how to adjust and formulate the optimal advertising strategy under the simultaneous effect of two factors of business reputation and competition, and how to optimize the allocation of resources for retailers in the traditional retail market and online sales channels to achieve better sales profits Provide a reference.

\section{Dual-channel supply chain competitive advertising model under the influence of business reputation}

The competition in the supply chain is the competition for market share through advertising and other strategies [10]. This article focuses on the competition of retailers in the supply chain for market share through different channels and analyzes the impact of advertising strategies 
on the profits of retailers. Suppose retailer $i(i=1,2)$ sells products with the same function in two sales channels, namely, the traditional retail market $r$ and the online electronic direct market. The two retailers compete in the market, and the degree of competitiveness depends on the investment in advertising. quantity. The dual-channel dynamic control model advertising system under the influence of business reputation is shown in [Figure 1].

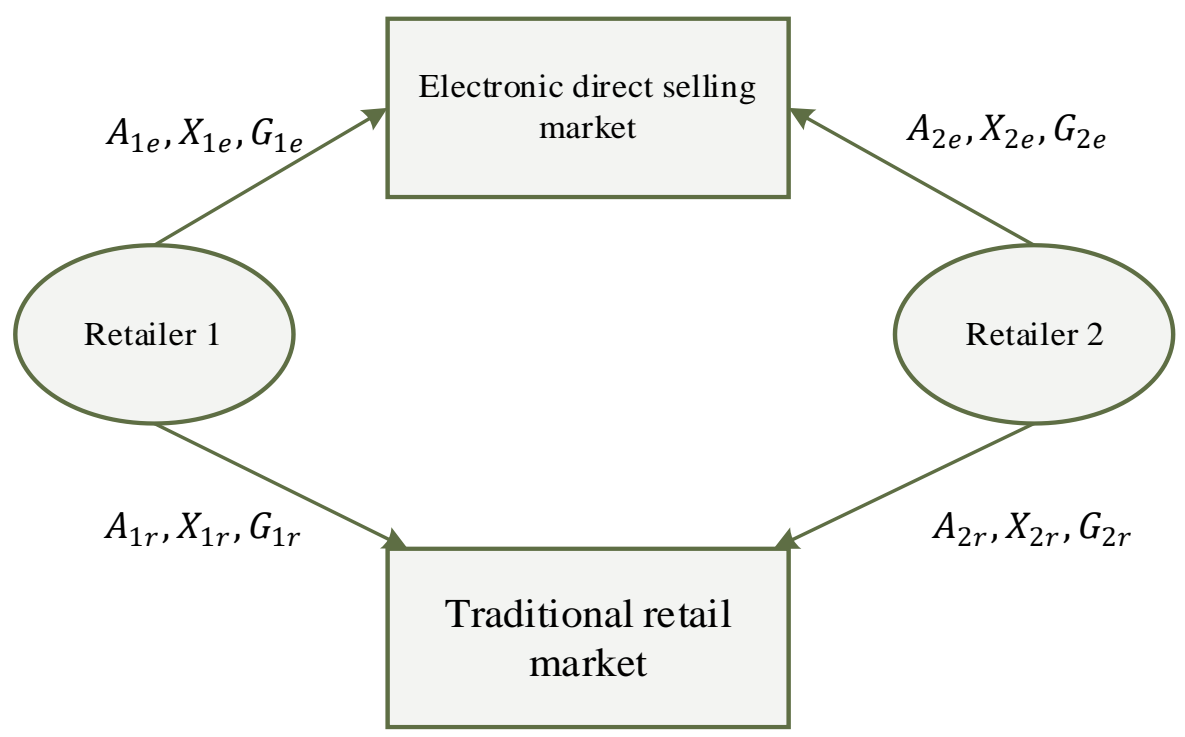

Figure 1. Dual-channel dynamic advertising system under the influence of business reputation

In reality, the commercial reputation of the product and the retailer's market share in a certain market is not static but change dynamically as the amount of advertising investment changes. This article considers the dual-channel supply chain competitive advertising strategy model under the influence of business reputation. The relevant symbols and their meanings are shown in [Table 1].

Table 1 Representation of related symbols

\begin{tabular}{|c|c|}
\hline symbol & Meaning \\
\hline$J_{i}$ & Retailer i's profit function \\
\hline$x_{i k}(t)$ & Retailer i's competitive share in market k \\
\hline$q_{i k}$ & Retailer i's first-order profit margin in market k \\
\hline$Q_{i k}$ & Retailer i's second-order profit margin in market k \\
\hline$b_{i k}$ & Retailer i's first-order marginal cost in market k \\
\hline$B_{i k}$ & Retailer i's second-order marginal cost in market k \\
\hline$G_{i k}(t)$ & Retailer i's business reputation in market k \\
\hline
\end{tabular}

For retailers, the main purpose is to maximize profits. The decision on advertising investment depends on the behavior of competitors as well as various factors in the current market. Retailers can gain market share through the amount of advertising investment. How to allocate between the two markets in the presence of competition and advertising investment has become the key to solving the current problem. 
The objective function of retailer I is as follows:

$$
J_{i}=\int 0 T e^{-\rho t}\left[\sum_{k=r, e}\left(q_{i k} \cdot x_{i k}(t)+\frac{1}{2} Q_{i k} x_{i k}(t)^{2}-b_{i k} \cdot A_{i k}(t)-\frac{1}{2} B_{i k} \cdot A_{i k}(t)^{2}\right)\right]
$$

Where the amount of advertising investment $A_{i k}$ is the decision variable, and $\rho$ is the discount rate of the retailer. In the period $0 \sim T$, the retailer's profit is deducted from its advertising input cost from its sales revenue.

The first consideration for consumers when choosing a product is the reputation of the product, that is, business reputation. Studies have shown [11][12] that the amount of advertising investment directly affects the product's commercial reputation. Assuming that the cost function of advertising is $C(A)=b A+12 B A^{2}$, where $A$ is the amount of advertising investment, $\mathrm{b}$ and $\mathrm{B}$ are their first-order and second-order cost factors, respectively. The dynamic evolution differential equation of advertising input $A$ and business reputation $G(t)$ is:

$$
\frac{d G_{i k}(t)}{d t}=\alpha A_{i k}-\beta G_{i k}(t), G(0)=G_{0} \geqslant 0
$$

Where $\alpha$ is the influence factor of advertising investment on brand business reputation, and $\beta$ is the attenuation coefficient of business reputation. In the actual market sales link, whether it is the traditional retail market or the electronic direct sales market when a brand has a good business reputation, consumers tend to associate with the brand's products, which is a positive promotion for the retailer itself. It harms the sales market of competitors' products. Consumers often have a sense of trust and preference for brands with good business reputations, reflecting those changes in business reputation directly affects the retailer's market share.

For the $2 \times 2$ structure environment, to simplify the research problem, suppose that there are only two retailers selling products in the market. Retailer 1 and retailer 2 are in a mutually competitive relationship. Therefore, in a particular market, their market share $x_{i k}(k=r, e)$ is valid for any time $t$ and market $k$. The fluctuation of business reputation has a direct impact on the market share. This article improves the dynamics of the market share in the original competitive environment. Model:

$$
\begin{aligned}
\frac{d x_{i_{1}, k}}{d t}= & \gamma_{i_{1}, k} G_{i_{1}, k}(t)-\gamma_{i_{2}, k} G_{i_{2}, k}(t)+ \\
& A_{i_{1}, k}(t) x_{i_{2}, k}-A_{i_{2}, k}(t) x_{i_{1}, k}
\end{aligned}
$$

Where $i_{1}, i_{2}=1,2, i_{1} \neq i_{2} ; \gamma$ represent the degree of influence of business reputation on market competition share, and $G_{i k} \geqslant 0$.

To solve the problem and obtain the optimal objective function, construct the Hamilton present value function of each retailer in different markets, and introduce the dynamic competition share model under the influence of business reputation, and construct the Hamilton function of retailer $i$ in the $k$ market. for: 


$$
\begin{aligned}
H_{i k} & =e^{-\rho_{i} t}\left[\sum _ { k = r , e } \left(q_{i k} x_{i k}(t)+\frac{1}{2} Q_{i k} x_{i k}(t)^{2}-b_{i k} A_{i k}(t)-\right.\right. \\
& \left.\left.\frac{1}{2} B_{i k} A_{i k}(t)^{2}\right)\right]+\sum_{k=r, e} \lambda_{k}^{i}(t)\left[\gamma_{i_{1} k} G_{i_{1} k}(t)-\gamma_{i_{2} k} G_{i_{2} k}(t)+\right. \\
& \left.A_{i_{1} k}(t)\left(1-x_{i_{1} k}(t)\right)-A_{i_{2} k}(t) x_{i_{1} k}(t)\right]+ \\
& \sum_{k=r, e} \frac{\partial H^{i}}{\partial G_{i k}}\left(\alpha A_{i k}(t)-\beta G_{i k}(t)\right)
\end{aligned}
$$

For the optimal solution of the quadratic equation, the Pontryagin principle of maximal value is used, and its control variables satisfy:

$$
\frac{\partial H_{i k}}{\partial A_{i k}}=0, i=1,2 ; k=r, e
$$

Obtain the control variable as:

$$
A_{i k}(t)=\frac{\lambda_{i k}\left(1-x_{i k}(t)\right)+\frac{\partial H_{i k}}{\partial G} \cdot \alpha}{e^{-\rho t} \cdot B_{i k}}-\frac{b_{i k}}{B_{i k}}
$$

It can be seen from the above expression that the linear equation of advertising investment is related to the cost coefficient and changes in business reputation. For the optimal open-loop strategy, the dynamic equation of the Lagrange multiplier is:

$$
\grave{\lambda}_{i k}=-\frac{\partial H^{i}}{\partial x_{i k}}, i=1,2 ; k=r, e
$$

The simple calculation is:

$$
\dot{\lambda}_{i k}=-e^{-r t}\left(q_{i k}+Q_{i k} \cdot x_{i k}\right)+\sum_{k=r, e} \lambda_{i k} \cdot \sum_{j=1, j \neq i}^{2} A_{j k}
$$

It is combined into a coupled equation system formed by $x_{i k}(t)$. And the Langrangian multiplier appears in the linear equation of the decision variable advertising input, that is to say, the market share in a certain time state can affect the decision-making by affecting the dynamic marginal benefit in a certain period. The value of the variable ultimately affects the maximum value of the objective function. The retailer's advertising strategy is a function of the current variable time. The two retailers face the same game, so they can be analyzed and discussed from the perspective of static feedback balance (to simplify the expression, the time $t$ is omitted in the subsequent analysis).

As for the decision analysis of the amount of advertising investment mentioned above, it is related to the parameter of the influence degree of business reputation on market competition, so it is necessary to analyze the related formula of business reputation. Here is the reference of Hamilton-Jacobi-Bellman Equation, for the retailer, the optimal profit function $H^{\prime}\left(G_{r}+G_{e}\right)$ must satisfy the following HJB equation: 


$$
\begin{aligned}
& \rho H^{\prime}\left(G_{r}+G_{e}\right)=\mathrm{m}\left(q_{i k} x_{i k}+\frac{1}{2} Q_{i k} x_{i k}^{2}-b_{i k} A_{i k}-\right. \\
& \left.\frac{1}{2} B_{i k} A_{i k}^{2}\right)+\lambda_{i k}\left(\gamma_{i k} G_{i k}-\gamma_{j k} G_{j k}+A_{i k}\left(1-x_{i k}\right)-\right. \\
& \left.\left.A_{j k} x_{i k}\right)+\frac{\partial H^{\prime}}{\partial G}\left(\alpha A_{i k}-\beta G_{i k}\right)\right) \\
& i=1,2 j=1,2 \text { 且 } j \neq i
\end{aligned}
$$

Solve the first-order equation on the right side of the above formula about the advertising investment $A_{i k}$, and substitute them together, and set $H^{\prime}\left(G_{r}+G_{e}\right)=C_{1} G_{i r}+C_{2} G_{i e}+C_{3}$, combined and sorted out:

$$
\begin{aligned}
& \rho\left(C_{1 c} G_{i r}+C_{2} G_{i e}+C_{3}\right)=\left(\lambda_{i r} \cdot \gamma_{i r}-C_{1} \beta\right) G_{i r}+ \\
& \left(\lambda_{i e} \cdot \gamma_{i e}-C_{2} \beta\right) G_{i e}+\left(q_{i k} x_{i k}+\frac{1}{2} Q_{i k} x_{i k}^{2}-b_{i k}\right. \\
& \frac{C_{i} \alpha-b_{i k}+\lambda_{i k}\left(1-x_{i k}\right)}{B_{i k}}- \\
& \frac{1}{2} B_{i k}\left\{\frac{C_{i} \alpha-b_{i k}+\lambda_{i k}\left(1-x_{i k}\right)}{B_{i k}}\right\}^{2}+ \\
& \left(\frac{C_{i} a-b_{i k}+\lambda_{i k}\left(1-x_{i k}\right)}{B_{i k}} \cdot\left(1-x_{i k}\right)-\right. \\
& \frac{C_{j} \alpha-b_{j k}+\lambda_{j k}\left(1-x_{j k}\right)}{B_{j k}} \cdot x_{i k}-\gamma_{j k} G_{j k}+ \\
& \left(\frac{C_{i} \alpha-b_{i k}+\lambda_{i k}\left(1-x_{i k}\right)}{B_{i k}} \cdot C_{i} \alpha\right), i \neq j
\end{aligned}
$$

Compare the coefficients of the $G_{i r}$ and $G_{i e}$ terms on the left and right sides of the above formula, and find the parameter value of the optimal profit function:

$$
C_{1}=\frac{\lambda_{i r} \cdot \gamma_{i r}}{\rho+\beta}, C_{2}=\frac{\lambda_{i e} \cdot \gamma_{i e}}{\rho+\beta}
$$

Substituting the above formula (11) into the advertising input formula (6), we can get:

$$
A_{i k}=\frac{\lambda_{i k}\left(1-x_{i k}\right)+\frac{\lambda_{i k} \cdot \gamma_{i k}}{\rho+\beta} \cdot \alpha}{e^{-\rho t} \cdot B_{i k}}-\frac{b_{i k}}{B_{i k}}
$$

Analyzing the above conclusions, it can be seen that in the dual-channel system under the influence of business reputation, the decision variables of the retailer's optimal advertising differential strategy are related to the retailer's market share and business reputation in a particular market at the current moment. The influencing parameters are related. When the retailer's market share in a certain market decay, he should increase his advertising investment in that market. When a brand's business reputation has a greater impact on the market's market share, he should increase the brand's market share. Advertising investment; otherwise, it should be reduced. 


\section{Data analysis}

According to the theoretical analysis of the dual-channel dynamic control model under the influence of business reputation, this chapter uses specific numerical values to study and analyze the model. The initial conditions assume that a certain specific time is $t=0$ and the period is $T=8$. When in this specific time, the model shows different vector diagrams for specific analysis, due to the mutual relationship between the two retailers in the market The antagonism is mainly discussed with the vector diagram of retailer 1 in the traditional retail market, in which the values of various parameters in [Table 2].

Table 2. Parameter values

\begin{tabular}{|c|c|c|c|}
\hline Parameter & Value & Parameter & Value \\
\hline$q_{1}$ & 0.8 & $q_{2}$ & 0.70 \\
\hline$Q_{1}$ & 0 & $Q_{2}$ & 0 \\
\hline$b_{1}$ & 0 & $b_{2}$ & 0 \\
\hline$B_{1}$ & 0.50 & $B_{2}$ & 0.60 \\
\hline$\rho_{1}$ & 0.05 & $\rho_{2}$ & 0.05 \\
\hline$\lambda_{1 r}$ & 0.60 & $\lambda_{2 r}$ & 0.60 \\
\hline$\lambda_{1 e}$ & 0.50 & $\lambda_{2 e}$ & 0.50 \\
\hline$\gamma_{1 r}$ & 0.25 & $\gamma_{2 r}$ & 0.20 \\
\hline$\gamma_{1 e}$ & 0.05 & $\gamma_{2 e}$ & 0.05 \\
\hline$\alpha_{11}$ & 0.30 & $\alpha_{2}$ & 0.40 \\
\hline$\beta_{1}$ & 0.01 & $\beta_{2}$ & 0.01 \\
\hline
\end{tabular}

Based on the analysis based on the data in [Table 2], the impact of the Lagrange multiplier on the retailer's profit is obtained, as shown in [Figure 2]. It can be seen from [Figure 2] that over time $t$, the marginal benefit of retailer $i(i=1)$ in the traditional retail market and the electronic network direct sales market's Lagrangian multiplier, that is, the market share, has gradually increased. As its advertising investment increases and its commercial reputation improves, it further affects the size of its market share, thereby increasing the efficiency of market competition. As time evolves, the marginal benefit of market competition will rise and eventually stabilize.

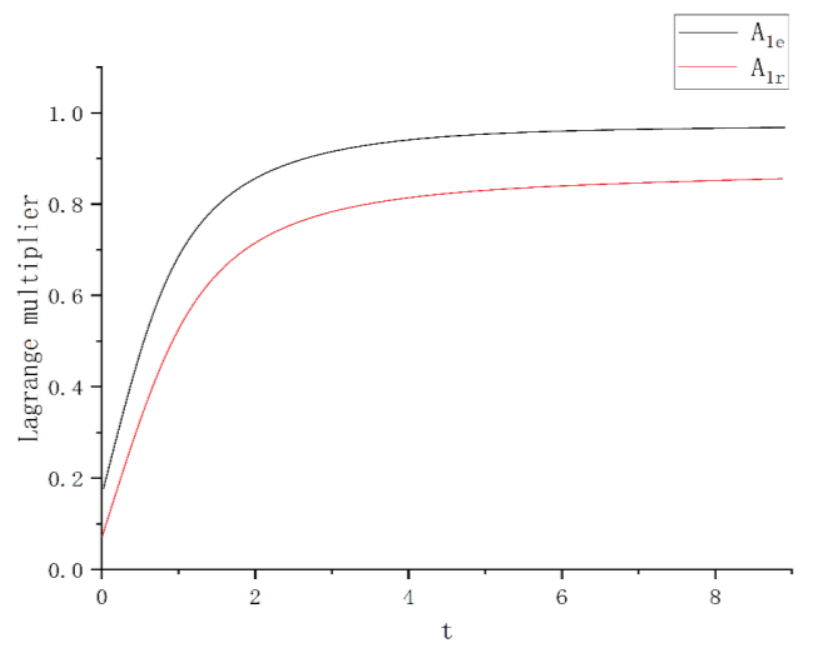

Figure 2. The influence of parameter $\lambda$ on retailer's profit 
[Figure 3] shows the time evolution of retailer 1's market share in the traditional retail market. It can be seen that with retailer 1's continuous advertising investment in the market, its product's market share continues to increase and eventually tends to the maximum. 1 . Analyzing the growth trend in [Figure 3], on the one hand, it is concluded that advertising investment has a positive effect on market share. On the other hand, it is indirectly inferred that advertising investment drives the improvement of brand business reputation and further promotes the growth of market share. For retailers, the size of the market share reflects the amount of profit. An appropriate advertising investment strategy is a necessary means for retailers to make profits.

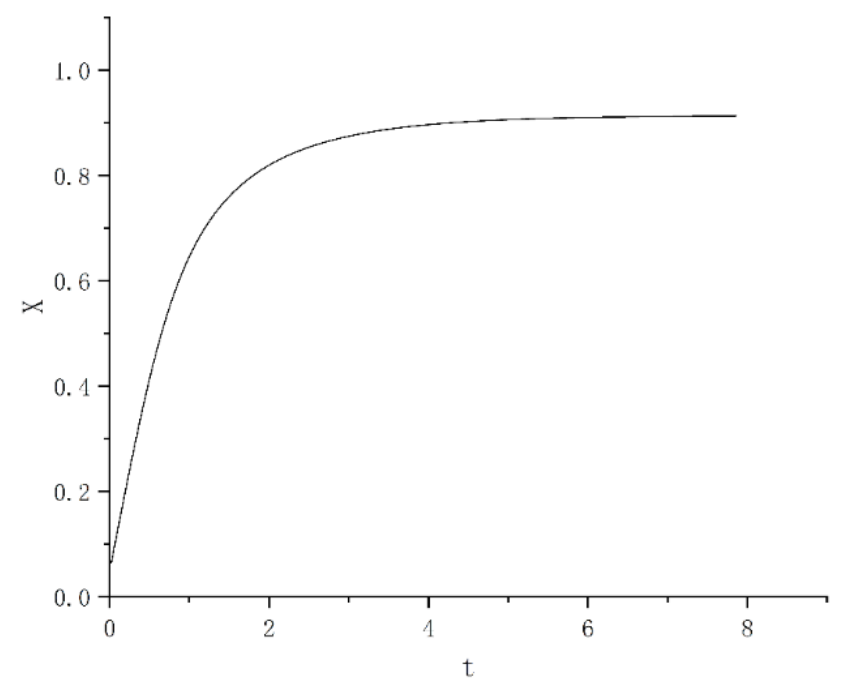

Figure 3. $X-t$ dynamic vector diagram

As shown in [Figure 4], the dynamic graph of the relationship between advertising investment and profit in retailer 1's traditional retail market in a specific environment. As can be seen from the figure, with the increase in advertising input in the first half of the period, the market share has gradually increased, and the profit has continued to increase. When the increase is greater than a certain peak, an optimal profit value will be obtained, and when this extreme value is exceeded the profit function decreases as the amount of advertising input increases. For the retailer to increase the amount of advertising investment in a specific market, it will positively promote the retailer's business reputation and market competition in the market. With the increase in advertising investment and the continuous improvement of market competition, the retailer's profit with increase, when the amount of advertising investment reaches a certain value, after the retailer's market share in the market reaches saturation, with the increase of advertising investment, accompanied by an increase in costs, the profit function shows a downward trend. 


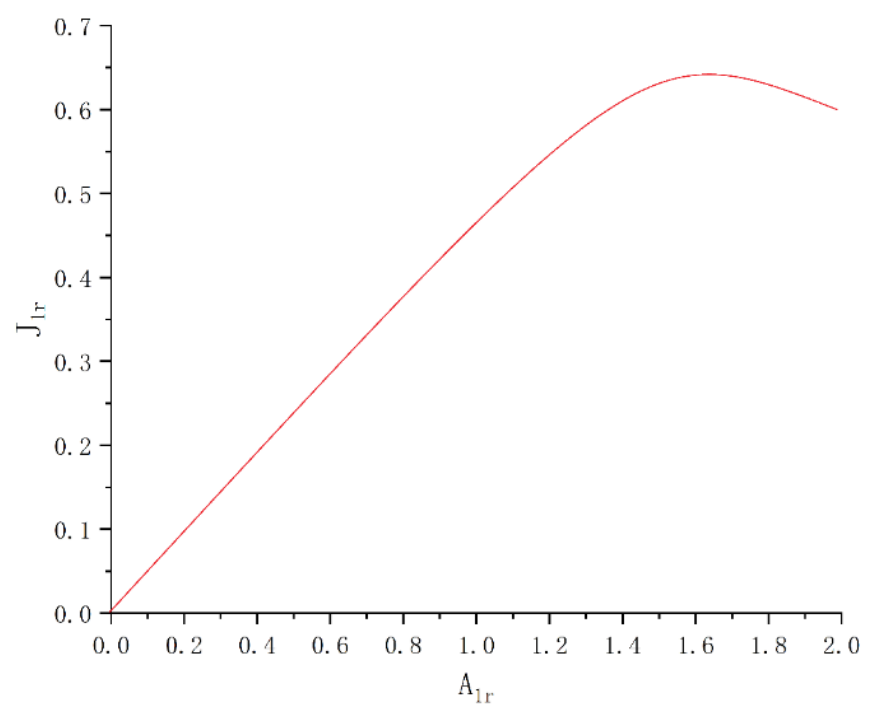

Figure 4. $J-A$ dynamic vector diagram

Under the dual-channel dynamic control model under the influence of business reputation provided in this article, two factors, the brand's business reputation, and the retailer's market competition will have an impact on the differential decision of advertising investment. Then this article changes the value of the business reputation influence coefficient $\gamma$ and the marginal benefit $\lambda$ of market competition, taking retailer 1 as an example to study the influence of business reputation and market competition on the optimal advertising decision A1r. When the value of $\gamma$ is large, $A_{1 r}$ increases with the increase of $\lambda$, and when the value of $\gamma$ is small, $A_{1 r}$ decreases with the increase of $\lambda$. When the brand's business reputation is good, it will have a positive effect on market competition and make the retailer's competition in the market more effective. Then the amount of advertising investment in the market should be increased. The good reputation of the brand's business reputation makes the marginal revenue of competition large, and the market with large marginal revenue will gain more market share for the same amount of advertising investment, so for retailers, what the market needs to do is to increase advertising investment quantity.

For retailers, the ultimate profit is the most concerned and important. Under the model of this article, by changing the amount of advertising input and market share in the objective function, the relationship between profit and advertising differential decision-making and market competition is analyzed from the perspective of static feedback equilibrium. When a retailer has a larger share in a particular market, profits will decrease as the amount of advertising investment increases. When a retailer has a small share in a particular market, profits increase with the increase in advertising input. Regardless of whether it is the traditional retail market or the electronic direct sales market, for a retailer, when the retailer has a dominant position in the competition in the market, then his advertising investment can be relatively reduced in the market and the other Increase investment in relatively less competitive markets. Assuming that the retailer's brand business reputation and market share have been maximized, then continuing to increase the amount of advertising investment will only bring about an increase in costs. On the contrary, when the retailer's brand business reputation is small and the market share is small, because there is more room for value-added, the increase in advertising 
investment at this time will increase the business reputation and market share, which will positively promote profits. increase.

Advertising, as the most direct marketing method for companies to compete for the market, has been valued since ancient times. Companies have been constantly adjusting their advertising investment strategies to increase their competitiveness. In real life, consumer consumption tends to be word-of-mouth, and a brand with a good reputation is more trusted and favored by customers. In the research of the market, retailers should learn more about factors such as product business reputation and market share. Whether it is the offline traditional retail market or the online electronic direct sales market, according to the actual situation, if the product has a higher marginal benefit and market space in the market, the retailer should make a suitable advertising investment strategy to improve the product The business reputation of the company attracts more consumer groups, gains more market share, and maximizes profits. On the contrary, when a product has poor marginal benefits or market saturation in a certain market, retailers should make corresponding adjustment plans and consider other market channels to obtain the best decision-making results. The research results of this paper can help companies analyze market competition in a certain sense, integrate various factors, and formulate the optimal advertising investment to help companies achieve the goal of maximizing profits. Given the characteristics of dual-channel competition, the following opinions and suggestions are put forward: Strictly abide by the principle of fair market competition. Healthy competition among enterprises. Pay attention to business reputation, constantly improve themselves, and win word of mouth. Advertise strategically, analyze market conditions carefully and rationally, and make reasonable arrangements.

\section{Conclusion}

With the development of network technology, electronic network sales have entered the world of consumers and impacted the traditional retail market. More and more companies have begun to look for broader business opportunities in the new market structure. Reasonable allocation of resources in the structure has become a difficult problem for current enterprises. To study the advertising investment of two retailer brands in the mixed dual-channel supply chain of electronic direct sales and traditional retail, this paper constructs a dual-channel supply under the influence of business reputation. Chain brand competition advertising strategy model. Using the Hamilton-Jacobi-Bellman equation, analyze the advertising investment and influencing factors under competitive conditions. The research results show that: First of all, in the dual-channel supply chain, the optimal differentiation strategy of advertising is not only affected by market competition but also related to the intensity of the influence of business reputation on market competition. Secondly, when the retailer's market share in a certain market is smaller, its sales volume will be restricted. It should increase advertising investment in this market, increase the retailer's market share in this market, and increase the margin of the market. Benefits should be reduced on the contrary. Finally, when a brand's commercial reputation has a greater impact on the market's market share, the advertising investment for the brand should be increased, thereby increasing the brand's commercial reputation in a specific market and promoting the retailer's market share. Possession ability, on the contrary, should be reduced. The research results of this paper can provide a reference for the dynamic advertising investment decision of the dual-channel supply chain under the influence of business reputation. 


\section{References}

[1] H. Oegut and B. Tas, "The influence of internet customer reviews on the online sales and prices in the hotel industry," Service Industries Journal, vol.32, no.2, pp.197-214, (2012)

[2] F. W. Lanchester, "Aircraft in warfare: The dawn of the fourth arm," University of California Constable Limited, pp.180-202

[3] M. Vidale and H. Wolfe, "An operations research study of sales response to advertising," Operations Research, vol.5, pp.370-381

[4] M. Nerlove and K. J. Arrow, "Optimal advertising policy under dynamic conditions,” Economica, vol.29, pp.129-142

[5] G. M. Erickson, "Empirical analysis of closed-loop duopoly advertising strategies," Management Science, vol.38, no.5, pp.1732-1749

[6] P. K. Chintagunta and N. Vilcassim, "An empirical investigation of advertising strategies in a dynamic duopoly," Management Science, vol.38, no.9, pp.1230-1244

[7] P. Davis, "Spatial competition in retail markets : Movie theaters," The RAND Journal of Economics, vol.37, pp.964-982, (2006)

[8] A. Buratto, L. Grosset, and B. Viscolani, "Advertising channel selection in a segmented market," Automatica, vol.42, no.8, pp.1343-1347, (2006)

[9] S. Jørgensen and G. Zaccour, “Differential games in marketing,” Springer Science, pp.164-170, (2012)

[10] G. Kimball, "Some industrial applications of military operations research methods," Operations Research, vol.5, pp. 201-204

[11] S. Jørgensen, S. P. Sigue, and G. Zaccour, “Dynamic cooperative advertising in a channel,” Journal of Retailing, vol.76, no.1, pp.71-92, (2000)

[12] N. Amrouche, G. Martin- Herran, and G. Zaccour, "Pricing and advertising of private and national brands in a dynamic marketing channel," Journal of Optimization and Applications, vol.137, no.3, pp.465-483, (2008) 
This page is empty by intention. 